\title{
O CONCEITO DE CLASSE SOCIAL EM ESTUDOS DE RECEPÇÃO BRASILEIROS
}

THE CONCEPT OF SOCIAL CLASS IN BRAZILIAN RECEPTION STUDIES

EL CONCEPTO DE CLASE SOCIAL EN ESTUDIOS DE RECEPCIÓN DE BRASIL

Rafael Grohmann

Doutorando, Universidade de São Paulo (USP)

rafael-ng@uol.com.br

Roseli Figaro

Doutora, Universidade de São Paulo (USP)

figaro@uol.com.br

\section{Resumo}

Neste artigo, discute-se a utilização do conceito de classe social em estudos de recepção clássicos e contemporâneos, desde o fim da década de 1970 até o ano de 2012, a partir de livros considerados representativos para o campo da Comunicação. Esses trabalhos são analisados criticamente e verificam-se as contribuições que trouxeram para a área ao abordarem seu objeto empírico a partir do conceito de classe social. Na parte final, retomamos a discussão sobre o conceito de classe social e procuramos discutir alguns dos desafios que o conceito de classe social traz para os estudos de recepção.

Palavras-Chave: Estudo de recepção. Classe social. Campo da comunicação

\section{Abstract}

In this paper, we discuss the use of the social class concept in the classic and contemporary reception studies, since 1970s at 2012s, from books considered representative in the communication area. These books are critically analyzed and we verify the contributions that it has brought for the area when they apply the social class in the empirical research. At the end, we return to the discussion of the concept of social class, bring the contribution of two authors who update the concept from the Brazilian reality. Finally, we discuss some of the challenges that the concept of social class brings to the reception studies.

Keywords: Reception studies. Social class. Communication area

\section{Resumen}

En este trabajo se analiza el uso del concepto de clase social em estudios clasicos y contemporáneos de recepción, desde finales de 1970 hasta el año 2012, de los libros representativos para el campo de la comunicación. Estos libros son revisados y verificados los aportes que han traído a la zona por abordar su objeto empírico del concepto de clase social. Al final, volvemos a la discusión sobre el concepto de clase social y tratamos de analizar algunos de los retos que el concepto de clase social aporta a los estudios de recepción.

Palabras clave: Estudio de recepción. Clase social. Campo de la comunicación 


\section{INTRODUÇÃO}

Os Estudos de Recepção, principalmente os advindos dos Estudos Culturais, possuíam uma preocupação política (Cevasco, 2003) que parece estar se dissolvendo nos estudos atuais de Comunicação. Sai de cena a exaltação "romântica" das resistências dos receptores frente aos produtos midiáticos ${ }^{1}$, entram os profetas exaltadores da tecnologia, muitas vezes colocando-a como variável autonomizada, priorizando as artimanhas de um indivíduo-usuário ou de um prosumidor na relação com a Internet.

Em um momento onde as narrativas midiáticas de superação pelo "mérito individual" estão em voga (Campanella, 2012; Ronsini, 2012), conceitos clássicos como "classe social” e “ideologia”, predominantes na época da constituição do campo da Comunicação no Brasil nas décadas de 1970 e 1980, hoje estão relegados a segundo plano.

Este artigo pretende recuperar a discussão sobre classe social nos Estudos de Recepção a partir de um levantamento de como aparece o conceito em alguns estudos, considerados como marcos e referências, alguns "clássicos" e outros mais contemporâneos. É importante destacar que não se pretende esgotar o assunto neste artigo, e neste primeiro momento não pretende analisar as produções discentes dos Programas de Pós-Graduação, trabalho este que tem sido sistematizado pelo Núcleo de Pesquisa Cultura e Recepção Midiática, coordenado pela professora Nilda Jacks (Jacks, Menezes e Piedras, 2008).

No entanto, um levantamento aleatório feito por Veneza Ronsini (2012) a partir de dados coletados junto ao grupo de pesquisa de Jacks nos dá indícios de que a problemática da classe social foi relegada à segundo plano nos Estudos de Recepção, e quando é utilizada, não aparece integrada à pesquisa.

$\mathrm{O}$ artigo, então, pretende apresentar como este conceito aparece em alguns estudos de recepção entre as décadas de 1970 e 2000 no Brasil, tomando como critério básico a representatividade do trabalho no campo científico da Comunicação - sendo um destes critérios ter um livro publicado sobre o assunto. A partir disso, retomamos a discussão sobre o conceito de classe social, do ponto de vista do materialismo histórico e procuramos levantar alguns dos desafios que o conceito de classe social traz para os estudos de recepção.

\footnotetext{
${ }^{1}$ Não concordamos também com esta perspectiva. Estamos apenas fazendo uma leitura, entre muitas possíveis, do cenário atual do campo da Comunicação. 


\section{ESTUDOS “CLÁSSICOS” DE RECEPÇÃO}

Em seu texto "Os Clássicos da Pesquisa de Recepção no Brasil”, Maria Isabel Orofino (1997) analisa os trabalhos de Ondina Fachel Leal (1985) e Carlos Eduardo Lins da Silva (1985). Aqui, agregamos dois estudos a eles: "O Rádio dos Pobres”, dissertação de mestrado de Maria Immacolata de Vassalo Lopes (1988) e "Cultura de Massa e Cultura Popular: leituras de operárias", de Ecléa Bosi (1978), mesmo este não sendo originalmente do campo da Comunicação e havendo controvérsias quanto à validade do termo "estudo de recepção". Entretanto, ele foi considerado por tratar da temática da classe social em um estudo que envolve "leitura de operárias".

Bosi recorre muito ao trabalho de Hoggart (1973), inclusive, com semelhanças descritivas em relação ao livro dele, mas é ao funcionalismo (tratado como "teoria psicossocial") que ela recorre no momento de analisar os resultados, com citações de Merton, por exemplo. Em sua obra, Bosi (1978) liga a problemática da recepção aos estudos dos efeitos, à psicologia, à retórica e à teoria literária.

Já o conceito de classe aparece somente ligado à economia, sendo que há utilizações de termos como "classe pobre", "cultura da pobreza" e "cultura média". "As classes A, B e C correspondem à classe alta, média e baixa de acordo com critérios econômicos: vemos que os grupos de renda mais alta leem mais jornais que os de renda menor" (Bosi, 1978, p. 175). Classe, neste sentido, é substituto de renda.

Bosi (1978) se dirige ao trabalhador como um "consumidor anônimo", como mero público-alvo, "debilitado em sua consciência o sentido e a significação de sua classe" (Bosi, 1978, p. 199). Ou seja, classe aparece como substituto de renda, utilizando-se de terminologias próprias do mercado (como A, B e C). Além disso, apesar de falar em "cultura popular" e "cultura operária" e ter muitas descrições sobre o assunto, estes termos não são discutidos ou conceituados.

Em geral, as pesquisas que tomam a problemática das classes têm uma preocupação política, procurando visibilizar, como sugere Thompson (1987), o "ponto de vista dos de baixo", compreendendo questões ideológicas e mostrando que o receptor não é um ente passivo. É o caso da pesquisa de Carlos Eduardo Lins da Silva (1985), que chega a falar em “mediação ideológica".

Ele procura entender "o que de fato significa o Jornal Nacional para pessoas que pertencem às classes trabalhadoras" (Silva, 1985, p. 51). A partir de uma pesquisa-ação com 
dois grupos de trabalhadores, em Lagoa Seca e Paicará, mostra como o receptor pode resistir às mensagens dos meios de comunicação, considerando ainda outros fatores de mediação, como organizações de bairro, por exemplo. No entanto, não há aqui as referências dos Estudos Culturais Britânicos: fala-se ainda em "efeitos" sobre os telespectadores.

No que tange ao conceito de "classe", trata-se somente de uma "ferramenta" descritiva no vocabulário do autor: afirma fazer um estudo com pessoas pertencentes às "classes trabalhadoras", mas este conceito nunca é definido, sendo, por vezes, substituído por "trabalhadores" ou pelo termo "comunidades" como sinônimos. Nota-se que o termo “comunidade" tem repercussão clássica na obra do sociólogo Ferdinand Tönnies (1995), definida como grupos pequenos e geralmente de um lugar "pré-industrial”, e se contrapõe à "sociedade", que seria própria dos grupos urbanos, com uma divisão do trabalho complexa. Ora, deste modo, a noção de classe não pode ser simplesmente substituída pela de comunidade. Não se define, por exemplo, qual a diferença entre uma "família operária" e uma "família operária de menor renda".

Os próximos dois estudos, contudo, trazem avanços à questão teórico-metodológica envolvendo o conceito de classe social. A dissertação de mestrado de Maria Immacolata Vassalo de Lopes (1988) faz uma análise ideológica do discurso e dos ouvintes dos programas radiofônicos Zé Bettio, Gil Gomes e Sílvio Santos. O conceito mais desenvolvido é o de marginalidade ou "estrato marginal", que aparece mais do que classe: "no Brasil, a marginalidade é vista em consonância com os processos de industrialização e de urbanização" (Lopes, 1988, p. 10). As populações marginais, então, são ligadas ao sistema de classes, com a autora chegando a falar em "classes marginais".

Uma das qualidades desta pesquisa é de ordem metodológica e conceitual, refinando e explicitando os conceitos utilizados. O conceito de classe aparece não somente a partir da renda, mas, principalmente, também a partir da situação de trabalho. Há um indicador empírico para a "existência marginal", que é dado pelo binômio "trabalho não qualificado/renda-trabalho mínima". Ainda são explicitados também os critérios de seleção dos informantes, a saber: 1) a situação de trabalho (ocupações não-especializadas, geralmente manuais); 2) a condição de ouvinte dos programas Zé Bettio, Gil Gomes e Sílvio Santos.

O trabalho de Ondina Fachel Leal (1985) também traz maior refinamento conceitual em relação à classe.. A autora traz muitas referências antropológicas para sua etnografia, trabalhando com temas caros à Antropologia, como o "estranho" e o "familiar" (Velho, 1978), os rituais (aplicado ao ato de assistir novelas) e os esquemas de parentesco, como em Lévi- 
Strauss (1982). Também recorre a Pierre Bourdieu e a sua noção de habitus, além de uma referência comum a outros estudos de recepção: Richard Hoggart.

Uma das diferenças do estudo de Ondina Leal em relação aos outros é o fato de a pesquisa abarcar dois grupos sociais, de classes sociais diferentes, considerando a partir de Bourdieu (2007) que a sociedade é relacional: separa-as em "classes populares" e "classes dominantes", ambos tomados como situações opostas, funcionando como "controle e parâmetro relativizador, entendendo a relativização etnográfica como um procedimento epistemológico fundamental" (Leal, 1985, p. 14). A autora afirma que escolheu trabalhar com um mundo "que se referia imediatamente a uma situação de classe diferenciada, por entender ser a situação de classe um locus privilegiado de significação” (Leal, 1985, p. 27).

Por que o conceito de classe? Para a autora, deve-se a uma intrínseca relação entre produção social e econômica e produção simbólica, se utilizando de um aparato conceitual bourdiano como "capital cultural" para afirmar reproduções da sociedade e legitimidades culturais que se relacionam com especificidades de classe.

Enquanto indicador empírico, o conceito de classe aparece a partir da unidade básica da família e das seguintes variáveis: 1) nível de renda; 2) participação no sistema de ensino; 3) acesso regular a bens simbólicos que não se restringem a produtos da "indústria cultural", como visitas a exposições de arte, o que a autora considera como gosto social legitimado.

Entre seus principais resultados está a maneira "ritual" de assistir à novela nas classes populares, contra uma maneira eventual das classes dominantes. Nesta eventualidade, há destaque para o excesso de "porquês" dos entrevistados da classe dominante. Para ela, a magia da televisão funciona de outra forma para as classes populares, que possuiriam maior domínio da gramática televisual. Ou seja, há uma romantização deste "outro", se ajustando às críticas apontadas por Lopes, Borelli e Resende (2002) quanto aos problemas dos primeiros estudos de recepção brasileiros.

Mas não podemos descartar todo o esforço despendido pelos estudos pioneiros. Mesmo reconhecendo o excessivo poder dado aos receptores e um excesso de descrição, sem conseguir chegar a um nível interpretativo maior, no caso de Leal (1985) temos que considerar o detalhamento conceitual e metodológico com relação ao conceito de classe social.

\section{OS ESTUdOS DE RECEPÇÃO E O CONCEITO DE CLASSE NA DÉCADA DE} 2000 
O livro "Vivendo com a Telenovela" (Lopes; Borelli; Resende, 2002) foi um marco na pesquisa de recepção no Brasil por apresentar uma "totalidade" não vista antes, com relação às estratégias multimetodológicas, a grande equipe de pesquisa e a perspectiva das mediações, o que permitiu classificações e maior refinamento da questão da recepção, como a análise de cada mediação e tentar abarcar todo o processo de comunicação, com rico material empírico. No que tange ao conceito de classe, logo no início do livro, as autoras destacam o “esquecimento da classe social", crítica válida para os dias atuais.

Este esquecimento se dá pelo nivelamento de todas as categorias identitárias, como gênero, idade e etnia. Por isso, elas consideram a diferença de classe não somente como uma "simples diferença", de alteridade, mas como a "que articula as demais a partir de seu interior e expressa-se por meio do habitus, capaz de entrelaçar os modos de possuir, de estar junto e os estilos de vida" (Lopes; Borelli; Resende, 2002, p. 45).

Se o referencial de Martín-Barbero (1995) perpassa toda a pesquisa, é, a exemplo de Leal (1985), à obra de Pierre Bourdieu que as autoras recorrem para tratar do tema da classe social, especificamente ao seu polêmico conceito de habitus. "O conceito de classe social aparece na presente pesquisa como diferença social que se expressa em habitus, que é produto de condicionamentos sociais associados à posição correspondente" (Lopes; Borelli; Resende, 2002, p. 45). Tentando mostrar como é esta diferença que articula as outras, as autoras tentaram aplicar a posição na etnografia do cotidiano familiar. A família é aqui, também, a unidade básica e é entendida como espaço social, cultural e de mediação das mensagens de telenovela. Inclusive, levando em conta o espaço social, há também esquemas de parentesco das famílias analisadas.

Considerando este cenário, o critério de classe social serviu para organizar a amostra da pesquisa, considerando o conceito de "posição de classe" a partir do bairro, a partir da tipologia "favelada, periferia, bairro de classe média e condomínio fechado de classe média alta". O indicador do "bairro" como dimensão de classe se mostrou frutífero empiricamente para a pesquisa, mas não se pode bastar enquanto conceito, enquanto única dimensão do conceito de classe social, como já mostraram outras pesquisas. Como resultados, a pesquisa mostrou a importância da classe enquanto "articulação":

Nos livros publicados no Brasil desde o ano de 2000, pudemos identificar, ainda, três trabalhos de destaque: "Desigualdades Sociais e Telenovelas", de Lília Junqueira (2010), “O 
Fascínio de Sherazade", de Roberta Manuela Barros de Andrade (2003) e "A Crença no Mérito", de Veneza Ronsini (2012) 2 .

Junqueira (2010) faz uma compilação de pesquisas de recepção em Pernambuco, Brasília e São Paulo, procurando fazer um estudo das desigualdades sociais via telenovelas. Sua pesquisa tem influências de Bourdieu e do sociólogo Jessé Souza (2006), a partir do seu arsenal teórico que reúne Charles Taylor e Axel Honneth. A pesquisa traz trechos das falas de receptores confrontadas com os discursos das novelas sobre classe média, individualismo e periferia. No entanto, a autora traz pouca discussão metodológica e fala de classes, mas reproduz o modelo de classe “ABCDE” sem problematiza-lo e não justificando o seu uso.

Em seu livro, Andrade (2003) faz um estudo de recepção da novela global "Suave Veneno" e tenta juntar uma "etnografia das práticas domésticas" com "etnografia do consumo cultural", principalmente a partir dos trabalhos de Bourdieu e Canclini. Sua pesquisa traz certa semelhança com a de Leal (1985), ao, por exemplo, colocar a família como unidade básica e classificar seus informantes em "classe popular" e "classe média". Ela ressalta a importância do conceito de classe para não considerar a audiência uma "massa atomizada". "O lugar que uma pessoa ocupa nas estruturas sociais pode ser considerado determinante para o acesso dessa pessoa aos diferentes discursos em jogo na formação social” (Andrade, 2003, p. 120).

Tendo como parâmetro principal a conceituação de classe de Bourdieu, Andrade (2003) tenta compreender a questão das classes médias a partir de Poulantzas e Wright Mills, ao abordar as posições contraditórias de classe. Já para definir a categoria de "popular", ela fala dos termos "pobres" (Alba Zaluar), povo (Canclini), massa (Adorno e Horkheimer) e operários (Bosi), utilizando para sua pesquisa, como informantes, operários e assalariados não especializados, além de trabalhadores por conta própria. Ressaltamos que a autora também categoriza seus informantes da "classe média" a partir da ocupação.

Já o trabalho de Veneza Ronsini (2012) é fruto de uma pesquisa de fôlego, fruto de um longo caminho $(2007 a ; 2007 b$; 2011) tentando compreender as relações entre comunicação e classes sociais, tendo, principalmente, o enfoque na juventude. Uma de suas maiores preocupações é que "na pesquisa de recepção, o foco em questões de identidade, diferença e consumo também implicou o afastamento da problemática da desigualdade e do poder" (Ronsini, 2011, p. 373).

\footnotetext{
${ }^{2}$ Há outros autores que, em maior ou menor medida, trabalham com a questão da "classe social", como Márcia Tondato (2009) e Bruno Campanella (2012), mas optamos pelos outros três trabalhos por serem livros publicados e que têm como uma das problemáticas centrais a questão da classe.
} 
No livro destacado (Ronsini, 2012), a preocupação central é compreender qual o papel do imaginário televisivo na elaboração de representações acerca da pobreza/desigualdade e como a telenovela contribui para a manutenção da ideologia meritocrática, que é a base para justificação da desigualdade no capitalismo. Na fundamentação teórica, a autora propõe uma combinação da teoria das mediações de Martín-Barbero com o modelo encoding-decoding de Stuart Hall, além de contribuições do sociólogo Jessé Souza (2006) acerca da desigualdade social brasileira. A partir da ideia de recepção como totalidade, sua pesquisa passou por três etapas, a saber: leituras da desigualdade e da ideologia meritocrática, visões da sociedade de classes e leituras das representações da pobreza/desigualdade na TV e na telenovela.

No que tange ao conceito de classe, a autora ressalta a importância da dimensão do critério ocupacional, mesmo sendo considerado imperfeito por autores neomarxistas porque “diz respeito à renda e a posições definidas no âmbito da relações técnicas de produção, enquanto as classes se caracterizam pela sua localização dentro das relações sociais de produção” (Ronsini, 2011, p. 379). Mesmo assim, Ronsini considera importante este indicador para delinear a amostra da pesquisa, com a ressalva de que o conceito de classe também tem que considerar os estilos de vida e culturas que são moldadas pelas relações de produção. Ela concentra o conceito de classe como centrado na experiência e na consciência parcial dos interesses materiais em jogo.

A amostra da pesquisa se dá a partir da classificação de Quadros e Antunes (2001) com base nas ocupações e classificada em alta (alta e média alta), média e popular (média baixa e baixa). Para Ronsini (2012, p. 31), "a noção de classes populares resolve o problema da heterogeneidade das categorias de trabalhadores urbanos, dos pobres (pobreza relativa) e dos humildes (média baixa) e está relacionada com a noção de cultura popular”.

Então, a partir destes estudos observamos alguns avanços nas discussões teóricas e metodológicas sobre classe social no Brasil em alguns casos, principalmente a partir de Ronsini (2012). No entanto, o conceito de classe social não tem o "eco" necessário no campo da Comunicação, ou, como diz Murdock (2009, p. 31), precisamos mostrar que "sob a praia jazem as pedras do calçamento".

Em todos os trabalhos, no entanto, o que se verifica é a dificuldade de, a partir da conceituação clássica de classe social, atualizar sua definição com base na realidade contemporânea e, sobretudo, empregar o conceito de forma que ele seja articulado com os processos de produção e circulação dos bens materiais e imateriais da cultura. Considerando os aspectos aqui analisados, vale retomar a discussão sobre o conceito classe social, conforme 
Marx e Engels, para, depois, tentar recorrer a autores contemporâneos no sentido de tornar o conceito mais próximo à nossa realidade. É o que se pretende fazer na parte final deste artigo.

\section{O CONCEITO DE CLASSE E O CAMPO DA COMUNICAÇÃO}

A dificuldade em se trabalhar metodologicamente com o conceito de classe social é um problema geral do método escolhido pelo pesquisador. Os trabalhos, em sua maioria, não se propõem a análise a partir do método do materialismo histórico e dialético, que toma em consideração o desenvolvimento das forças produtivas e as relações de produção que o engendram e dele derivam. Um segundo problema está no precário intercâmbio dos cursos de comunicação com áreas do conhecimento como história, sobretudo do Brasil, sociologia, economia e política, como se o campo da comunicação pudesse passar ao largo dessas disciplinas, sem sofrer um esvaziamento teórico e epistemológico. Um terceiro problema é o uso do termo classe social como sinonímia de nível socioeconômico. Esse uso é bastante recorrente em pesquisas que classificam os consumidores em níveis $\mathrm{A}, \mathrm{B}, \mathrm{C}, \mathrm{D}, \mathrm{E}$; ou ainda, com base nesses níveis de capacidade de consumo.

Para estudar a comunicação e as classes sociais a pergunta primeira, feita pelos economistas clássicos bem como por Marx e Engels, continua valendo: de onde vêm as riquezas? Vem do valor que se dá ao trabalho, ou melhor, do valor criado pelo trabalho e que se pode acumular. Ao longo da história, as classes vão se alterando à medida que ocupam lugares diferentes na produção e/ou apropriação de riquezas. Conforme as sociedades vão se especializando, em termos das relações sociais decorrentes do desenvolvimento das forças produtivas, as classes vão se alterando.

Nesse sentido, a questão inicial que se coloca para o pesquisador é a de ele assumir ou não o ponto de vista de que as classes sociais se relacionam por meio do poder que detém sobre as riquezas produzidas. Há classes que produzem riquezas e não têm poder sobre os meios de produção e nem mesmo poder de acumular riquezas produzidas por outros; há classes que se estruturam exatamente por deterem o poder privado sobre os meios de produção e sobre o valor do trabalho realizado por outros, manifestas na forma do capital.

Os que vivem exclusivamente do trabalho remunerado por meio de salário são aqueles a que Marx chamou de proletariado, incluindo nessa classe os trabalhadores do campo sem posse da terra. Há que se referir também aos membros da classe que se dedicam à gestão do capital e que por essa tarefa amealham mais do que salário, são captadores de renda, 
tornando-se potenciais parceiros do capital, porque dispõem de uma parte do lucro do capitalista, o que lhes permite atuar no cenário do capital por meio do mercado financeiro e da aquisição de propriedades. Por outro lado, entre os pequenos proprietários de negócios do campo e da cidade há uma miríade de situações de classe.

Parece-nos que, no campo da comunicação, a questão central nos dias que correm é a tentativa de se tratar da categoria classe social sem se considerar as questões do trabalho, ou seja, das alterações que ocorrem no meio técnico científico (Santos,1996) no tocante ao desenvolvimento das forças produtivas e, em decorrência, no capitalismo. Os meios de comunicação, entendidos também como meios de produção (Williams, 2011), e os processos de comunicação compõem contemporaneamente a nova face do sistema do capital (Olivesi, 2006). Aspecto que coloca a problemática das classes sociais como questão sobre a qual a área da comunicação deve se debruçar e dar contribuições. Se a posse de e o acesso a tecnologias de informação e comunicação têm contribuído para as transformações nos perfis das classes tradicionais, as mudanças ocorridas nos processos de produção, que redesenham os perfis das classes, não alteram, no entanto, a forma de contraposição de suas relações. São, no fundamental, relações orientadas por interesses contrários, pelo confronto capital trabalho.

As dificuldades conceituais que se apresentam são decorrentes da complexidade do sistema capitalista, e, sobretudo, das disputas ideológicas frente às derrotas políticas dos movimentos por emancipação social. Aspectos que dificultam, mas não descartam a necessidade e a importância de análises mais aprofundadas sobre a relação capital trabalho.

Assim, não se pode diminuir a importância do papel das formas de aquisição de bens culturais no relacionamento entre as classes e como esses bens influenciam a relação entre as classes. A dimensão ideológica do prestígio social de uma classe como tal é atravessada por tais relações. Daí a conveniência de estudos de recepção que consideram como se dá a apropriação dos bens culturais pelas distintas classes sociais e como esses bens são utilizados para reconhecimento social. Tanto os estudos de Ronsini (2012) como os de Lopes; Borelli; Resende (2002) consideram tais especificidades.

Quando se salienta a relevância de se considerar as práticas culturais para entendermos o processo de recepção dos meios de comunicação, buscam-se articulações de pesquisas que revelem as consonâncias e as dissonâncias entre posições de classe, consumo cultural, representações sociais e produção de sentidos. Marx e Engels, em A Ideologia Alemã, salientam: "é a existência social que determina a consciência"(2007,p.94), por existência 
social compreende-se o conjunto de formas concretas de viver a vida. Eagleton (2012, p.121), comentando a relação que Marx estabelece entre consciência e vida prática, afirma:

\begin{abstract}
Se com 'ser social' queremos dizer o tipo de coisa que fazemos, a consciência já se encontra aí envolvida. Não é como se a consciência existisse de um lado de um divisor de águas e nossas atividades sociais de outro. Não é possível votar, beijar, apertar mãos ou explorar o trabalho imigrante sem significados e intenções.
\end{abstract}

Ao se estudar a recepção dos processos de comunicação, considerando as relações entre as classes sociais e o lugar que o indivíduo/sujeito ocupa nessas relações, procura-se compreender de maneira objetiva como os significados, intenções e ideologias são construídos.

Portanto, os estudos de recepção podem contribuir, ao considerarem as classes sociais como categoria de análise, tendo-as na dimensão de sua complexidade, lugar social de produção de sentido, de pontos de vista. Nunca se distanciando da compreensão de que as classes se definem por oposição e que redundam em relações de poder. A classe dominante, assim o é porque suas ideias dominam. Fato que não invalida a existência de outras ideias, muitas vezes, ainda não organizadas como ideias contra-hegemônicas.

Essas sintéticas considerações sobre os estudos que contemplam o conceito de classe social no Brasil serão aprofundadas e pretendemos, a partir delas, desenvolver análises que possam contribuir com os pesquisadores que problematizam as relações de classe nos estudos de recepção.

\title{
REFERÊNCIAS
}

ANDRADE, Roberta Manuela Barros de. O Fascínio de Sherazade: os usos sociais da telenovela. São Paulo: Annablume, 2003.

BOSI, Ecléa. Cultura de Massa e Cultura Popular: leituras de operárias. Petrópolis: Vozes, 1978.

BOURDIEU, Pierre. A Distinção: crítica social do julgamento. São Paulo: Edusp, 2007

CAMPANELLA, Bruno. Os Olhos do Grande Irmão: uma etnografia dos fãs do Big Brother Brasil. Porto Alegre: Sulina, 2012

CEVASCO, Maria Elisa. Dez Lições sobre Estudos Culturais. São Paulo: Boitempo, 2003.

EAGLETON, Terry. Marx estava certo. Rio de Janeiro: Nova Fronteira, 2012.

HOGGART, Richard. As Utilizações da Cultura: aspectos da vida cultural da classe trabalhadora - vol. I. Lisboa: Ed. Presença, 1973. 
JACKS, Nilda; MENEZES, Daiane; PIEDRAS, Elisa. Meios e Audiências: a emergência dos estudos de recepção no Brasil. Porto Alegre: Sulina, 2008.

JUNQUEIRA, Lília. Desigualdades Sociais e Telenovelas: relações ocultas entre fíç̧ão e reconhecimento. São Paulo: Annablumme, 2010.

LEAL, Ondina Fachel. A Leitura Social da Novela das Oito. Petrópolis: Vozes, 1985.

LÉVI-STRAUSS, Claude. As Estruturas Elementares do Parentesco. Petrópolis: Vozes, 1982.

LOPES, Maria Immacolata Vassallo de. O Rádio dos Pobres: comunicação de massa, ideologia e marginalidade social. São Paulo: Loyola, 1988.

LOPES, Maria Immacolata Vassalo de; BORELLI, Sílvia; RESENDE, Vera. Vivendo com a Telenovela: mediações, recepção, teleficcionalidade. São Paulo: Summus, 2002.

MARTÍN-BARBERO, Jesús. Dos Meios às Mediações: comunicação, cultura e hegemonia. Rio de Janeiro: Ed. UFRJ, 1995.

MARX, Karl, ENGELS, Friedrich. A ideologia alemã. São Paulo: Boitempo, 2007.

MURDOCK, Graham. Comunicação Contemporânea e Questões de Classe. Matrizes. Ano 2, n. 2, p. 31-56, 2009.

QUADROS, Waldir; ANTUNES, Davi. Classes Sociais e Distribuição de Renda no Brasil dos anos noventa. Cadernos do CESIT, n. 30. Campinas, 2001.

OLIVESI, Stéphane. La communication au travail : une critique des nouvelles formes de pouvoir dans les entreprises. 2.ed. Grenoble, PUG, 2006.

OROFINO, Maria Isabel. Os clássicos da Pesquisa de Recepção no Brasil. In : XX Congresso Brasileiro de Ciências da Comunicação - Intercom. Anais do Intercom, 1997. Santos-SP.

POCHMANN, Márcio. Nova Classe Média? - O trabalho na base da pirâmide social brasileira. São Paulo: Boitempo, 2012

RONSINI, Veneza. Mercadores de Sentido: consumo de mídia e identidades juvenis. Porto Alegre: Ed. Sulina, 2007

Mídia, Cultura e Classe: a ordem da diferença. In: XVI Encontro Anual da Associação Nacional dos Programas de Pós-Graduação em Comunicação, Curitiba, 2007b. In: Anais da Compós, 2007b. Disponível em $<$ http://www.compos.org.br/data/biblioteca_158.pdf> Acesso em: 09 out. 2012.

Apontamentos sobre classe social em um estudo de recepção. In: FREIRE FILHO, João; BORGES, Gabriela (org.). Estudos de Televisão: diálogos Brasil-Portugal. Porto Alegre: Sulina, 2011, p. 297-338. 
. A Crença no Mérito e a Desigualdade: a recepção da telenovela do horário nobre. Porto Alegre: Sulina, 2012.

SANTOS, Milton. Técnica espaço tempo. Globalização e meio técnico-científico informacional. São Paulo: Hucitec, 1996.

SILVA, Carlos Eduardo Lins da. Muito Além do Jardim Botânico. São Paulo: Summus, 1985.

SOUZA, Jessé. A Construção Social da Subcidadania: para uma sociologia política da modernidade periférica. Belo Horizonte: Ed. UFMG, 2006.

Os Batalhadores Brasileiros: nova classe média ou nova classe trabalhadora? Belo Horizonte: Ed. UFMG, 2010.

THOMPSON, Edward Palmer. A Formação da Classe Operária Inglesa. Vol I. Rio de Janeiro: Paz e Terra, 1987.

TONDATO, Márcia. Os Gêneros Televisivos no cotidiano da recepção de televisão. In: II Colóquio Binacional Brasil-México de Ciências da Comunicação. Anais do II Colóquio..., 2009. Disponível em

$<$ http://www.espm.br/ConhecaAESPM/Mestrado/Documents/COLOQUIO\%20BXM/S4/mar cia\%20tondato.pdf $>$. Acesso em 09 out. 2012

TÖNNIES, Ferdinand. Comunidade e Sociedade. In: MIRANDA, Orlando (org.). Para ler Ferdinand Tönnies. São Paulo: Edusp, 1995.

VELHO, Gilberto. Observando o Familiar. In: NUNES, Edson de Oliveira. A Aventura Sociológica: objetividade, paixão, improviso e método na pesquisa social. Rio de Janeiro: Zahar, 1978, p. 36-46.

WILLIAMS, Raymond. Cultura e materialismo. São Paulo: Editora Unesp. 2011.

Original recebido em: 20/04/2014

Aceito para publicação em: 20/07/2014 
Sobre os autores

Rafael Grohmann

Doutorando e Mestre em Ciências da Comunicação pela Universidade de São Paulo (USP). Professor do curso de Jornalismo do FIAM-FAAM - Centro Universitário. Membro do Centro de Pesquisas em Comunicação e Trabalho (CPCT / ECA-USP).

\section{Roseli Figaro}

Professora livre-docente do Programa de PósGraduação em Ciências da Comunicação da Universidade de São Paulo (USP). Chefe do Departamento de Comunicações e Artes da ECA-USP. Coordenadora do Centro de Pesquisas em Comunicação e Trabalho (CPCT / ECA-USP) 